\title{
Editorial: Submarine Active Faults: From Regional Observations to Seismic Hazard Characterization
}

\author{
Hector Perea ${ }^{1,2,3 *}$, Sara Martínez-Loriente ${ }^{3}$, Jillian Maloney, \\ Francesco Emanuele Maesano ${ }^{5}$ and Paola Vannucchi ${ }^{6}$ \\ ${ }^{1}$ Facultad de Ciencias Geológicas, Universidad Complutense de Madrid, Madrid, Spain, ${ }^{2}$ Geosciences Research Division,

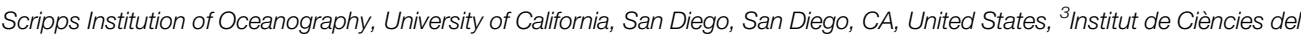 \\ Mar, Consejo Superior de Investigaciones Cientificas, Barcelona, Spain, ${ }^{4}$ Department of Geological Sciences, San Diego State \\ University, San Diego, CA, United States, ${ }^{5}$ stituto Nazionale di Geofisica e Vulcanologia, Rome, Italy, ${ }^{6}$ Dipartimento di Scienze \\ della Terra, Università degli Studi di Firenze, Florence, Italy
}

Keywords: active tectionics, paleoseismology, marine geology and geophysics, seismic hazard, seismotectonics, active faults

Editorial on the Research Topic

Submarine Active Faults: From Regional Observations to Seismic Hazard Characterization

Since the beginning of the XXI Century, our society has witnessed a number of catastrophic earthquakes with devastating consequences (e.g., Sumatra 2004, Haiti 2010, Japan 2010, Nepal 2015, Italy 2009 and 2016). Localizing the active faults and understanding their earthquake history is key to improve modern probabilistic seismic hazard assessment (PSHA) and, thus, to mitigate the consequences of future events. Seismicity models to characterize the earthquake frequency in a region in PSHA studies have been traditionally based on archaeological, historical and instrumental earthquake records. However, the rapid advance of active tectonics and paleoseismological studies has resulted in the development of seismicity models for faults, since they allow characterizing the active faults, reconstructing their 3D geometry at depth, and determining their past earthquake history and seismic potential based on the interpretation of the geological record.

Traditionally, active tectonics and paleoseismological research had been mainly conducted to study onshore active faults. However, the occurrence of the offshore Sumatra (2004) and Japan (2010) earthquakes and consequent tsunamis, which caused tens of thousands of casualties and extensive and severe damage and economic losses, have brought into sharp focus the need to better understand the geohazards related to submarine active faults. In the last few years, the availability of offshore geological and geophysical data at various scales (e.g., deep and shallow borehole, wide angle seismic profiles, tomography, $3 \mathrm{D}$ and $2 \mathrm{D}$ seismic reflection surveys, high resolution bathymetry or seafloor imaging) has allowed for a better definition of offshore fault systems. These studies focused on accurately constraining the kinematic, architecture and linkage of active faults, and, in some cases, identify recent earthquake ruptures or recognize and date individual events. In addition, underwater active tectonics and paleoseismological studies benefit from: (1) low erosional rates that preserve fault morphology and segmentation; (2) continuous sedimentation in time and space that allows for local and/or regional stratigraphic and chronostratigraphic correlations; (3) multiscale seafloor mapping and sub-seafloor seismic imaging; and 4) absence-or lowest amount-of human modification.

This Research Topic includes fourteen published articles focused in the study of underwater active tectonic regions or active fault systems around the world (Figure 1). They use different datasets (i.e., bathymetry, seismicity from a local seismic network, sub-bottom profiling, reflection seismic profiles or sedimentary cores) to identify and characterize the seismic cycle of active faults using multidisciplinary approaches and innovative methodologies. The main goal of this Research Topic has 


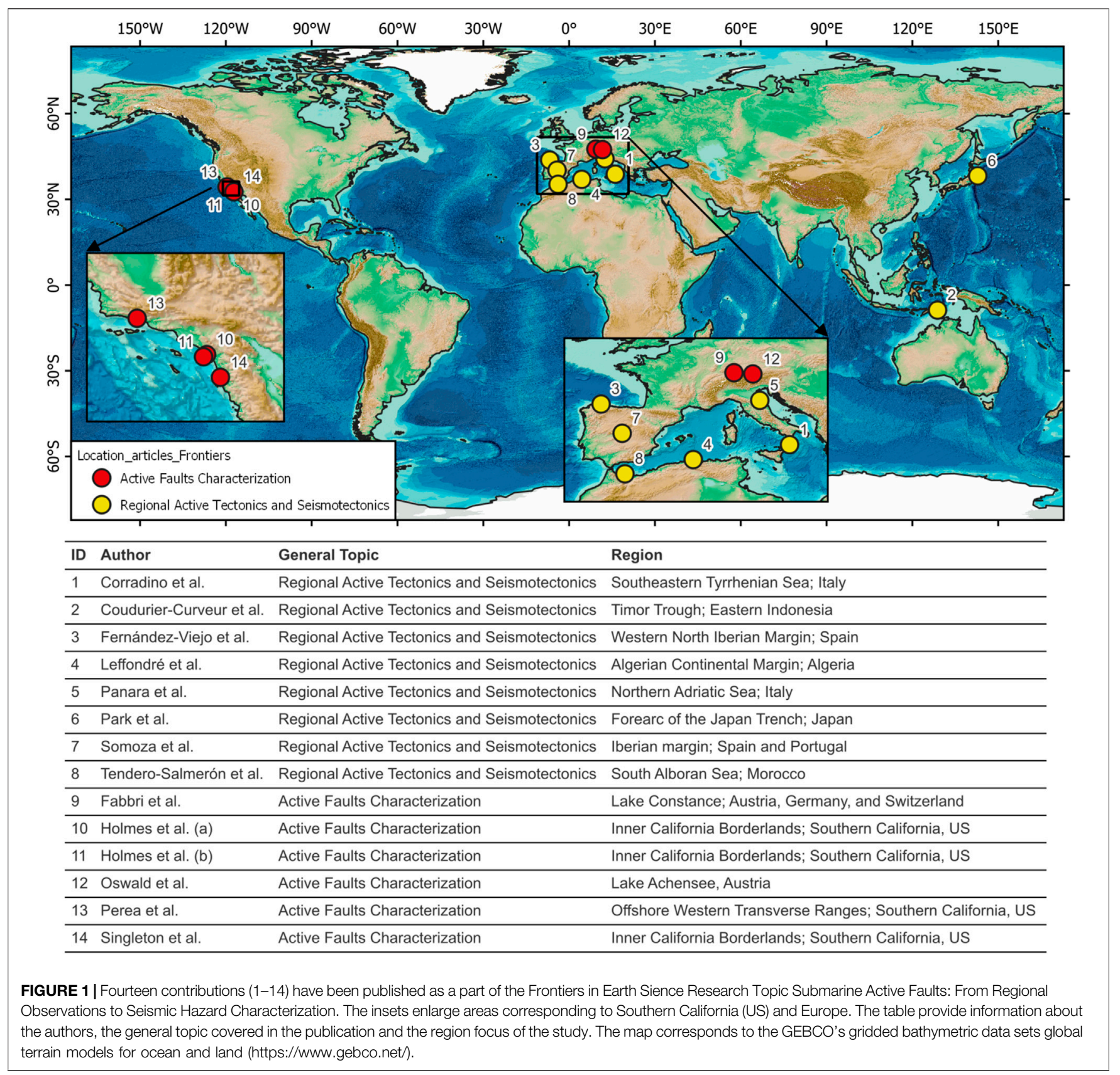

been to show the present advance in underwater active tectonics and paleoseismology in order to improve our understanding about the seismic and tsunami hazard. Here we provide a short review of the contributions grouped by the main topics.

\section{REGIONAL ACTIVE TECTONICS AND SEISMOTECTONICS}

Corradino et al. present a multiscale structural analysis method based on marine seismic reflection data and multibeam bathymetry and they test this approach on the Sant'Eufemia Gulf - southeastern
Tyrrhenian Sea (Italy). This analysis allows to reconstruct the structural pattern of the fault systems and distinguish between shallow, non-seismogenic active faults, and deep, seismogenic blind faults. The authors identify the occurrence of three major tectonic events since the Late Miocene, which may represent the response of the upper plate to a tear fault on the lower plate. In addition, the authors suggest that the seismogenic source of the large earthquake that struck the western Calabrian region in 1905 may be located below the Maida Ridge, in the Sant'Eufemia Gulf.

Coudurier-Curveur et al. use multibeam bathymetry and $2 \mathrm{D}$ seismic reflection data acquired along the Timor Trough (Eastern Indonesia) to characterize the location, nature, and 
geometry of active faults. The analysis of the dataset reveals that the area shows two styles of deformation, underthrusting and frontal accretion. This change may depend on the thickness of the incoming and underthrusting sediments, the vergence of inherited normal faults within the continental shelf, and the depth of the décollement. Based on the observed interchanging deformation style, the authors identify a mechanical and seismic segmentation along the Banda arc collision front and discuss the implications for earthquake and tsunami hazards in the region.

Fernández-Viejo et al. process and analyze offshore seismicity in the western North Iberian Margin (north Spain) from local seismic networks. The location and distribution of offshore earthquakes suggests that they may be produced by the intersection of the Cantabrian fault, an oblique dextral-reverse fault, with other crustal scale structures. Together with the Ventaniella fault, its continuation onshore, they represent a seismotectonic boundary separating two crustal blocks; to the west there is moderate-to low-magnitude but persistent seismicity, whereas to the east the seismicity is practically absent. The authors conclude that the different behavior may be reflecting different crustal mechanical properties and tectonothermal regimes.

The transition from a passive to an active continental margin and subduction initiation are topics discussed by Leffondré et al. using deep seismic reflection post-stacked data acquired along the Algerian continental margin, where the diffuse plate boundary between Africa and Eurasia is localized. The analysis of their dataset reveals clear margin segmentation and significant changes in its tectonic signature. Both observations may be related to inherited heterogeneities in the geometry of the Algerian margin and in the Miocene thermal state due to diachronous opening of the basin and magmatic imprint. The identified south-dipping blind thrusts may have the potential to produce large earthquakes (Mw 8.0).

Panara et al. analyze a dense dataset of $2 \mathrm{D}$ seismic reflection profiles and wells to perform a 3D structural reconstruction of eleven buried thrusts of the Northern Apennines chain in a near offshore sector of the northern Adriatic Sea (Italy), a low-strain rate region that nonetheless experienced significant historical earthquakes. The authors propose a probabilistic approach in estimating the slip history of four faults for the past $4 \mathrm{Myr}$ to account for displacement and age uncertainties. The analysis highlights an exponential slip reduction implying a decelerating slip-rate pattern. The slip histories also reveal an asynchronous activation proceeding from the inner to the outer thrusts, being the youngest structure the fastest during the last $0.4 \mathrm{Myr}$.

Park et al. identify landward-dipping normal faults associated to mantel helium anomalies in the forearc of the Japan Trench, based on the interpretation of pre-stack depth migrated multichannel seismic profiles and sub-bottom profiling. Their analysis reveals those normal faults as possible conduits for mantle-derived fluids in the coseismic slip area of the Tohoku 2011 earthquake ( $\mathrm{Mw}$ 9.0). The occurrence of this large earthquake may have reactivated pre-existing normal faults and make them more permeable allowing the migration of the fluids towards the seafloor. Locally elevated fluid pressures can decrease the effective normal stress for the fault plane, facilitating a shallow coseismic slip to the trench and local tsunami. Finally, the authors identify a possible shear zone and suggest that it could be associated with more intense basal erosion of the overlying plate.

Somoza et al. make a synthesis of submarine active faults around the Iberian margin focused on their geophysical characterization and the analysis of their development in the framework of the present plate organization. Based on their observations and the available bibliography they produce a synthesis map with the main active faults, showing that the major deformation is localized in the southern Iberian margin. The authors propose that the distribution of the active faults and the seismicity may be explained by the present-day NNW-SSE compressional stress field related to the convergence between the Eurasia and Africa plates.

Tendero-Salmerón et al. present an automated throw backstripping method to characterize the evolution of tectonic activity in wide fault zones. They apply the method to a large number of faults imaged on high-resolution seismic profiles in the Al Hoceima Bay (Alboran Sea), an area affected by three major earthquakes since 1994. Results show a westward migration of the deformation with quickly increasing deformation rates in the most recent time frames, which might be the consequence of the movement of the South Alboran indenter towards the NW and the displacement of the Rif towards the SW.

\section{ACTIVE FAULTS CHARACTERIZATION}

Using both newly acquired and vintage multi-channel seismic data, Fabbri et al. reveal the presence of 28 Quaternary faults in the overdeepened basin of Lake Constance (Austria, Germany, and Switzerland), located within the North-Alpine Molasse Basin. The analysis of the bathymetry shows a major fault, traceable to Cenozoic bedrock, that offsets of the lake bottom and interpreted as northward continuation of the St. Gallen Fault Zone. Seismic data and short sedimentary cores provide evidence of significant sediment thickness changes across this fault and surface-rupture related turbidites, all indicating repeated activity on the fault.

Holmes et al. (a) present high-resolution 3D P-Cable Boomer seismic data acquired along the Newport-Inglewood/Rose Canyon (NIRC) fault offshore San Onofre (Southern California, US). The analysis of the data shows the presence of a prominent step-over between different strike-slip fault segments and reveals that the deformation results in transpression and folding that structurally controls the width of the continental shelf in this region. In addition, the sedimentary units onlapping over the observed folds (i.e., anticlines) and radiocarbon dates indicate that the deformation in this section of the NIRC started around 560-575 kyr BP.

The analysis of a 3D seismic P-Cable sparker data shown by Holmes et al. (b) has been key to characterize the geometry and linkage in the San Mateo and San Onofre fault trends in the Inner California Borderlands (Southern California, US). The new observations may support that the tectonic deformation 
along these trends is best explained by left lateral step-overs along the predominantly right lateral strike-slip fault systems than a regional blind thrust model, as previously proposed. In addition, onlapping undeformed turbidite layers reveal that both major fault systems may have been inactive since the middle to late Pleistocene (between 184 and $368 \mathrm{kyr}$ ).

The interpretation of high resolution seismic profiles and the analysis of sediment cores have allowed Oswald et al. to carry out an on-fault and off-fault paleoseismological study in the inneralpine lake Achensee located in the slowly but actively deforming European Eastern Alps (Austria). The on-fault study has revealed that the Salzgraben-Eben thrust has produced three events (min. Mw 6.0-6.5), one at $\sim 8.3 \mathrm{ka} \mathrm{BP}$ and two in the Late Glacial. Complementary, the off-fault study has provided evidence of eight earthquakes during the last $11 \mathrm{kyr}$, one occurred in CE 1670. In addition, the authors also highlight the advantages of carrying on- and off-fault paleoseismological studies in mountain lakes and the characteristics to look for in these type of studies in these environments.

Using a high-resolution seismic CHIRP dataset, Perea et al. identify vertical displacement related to different active blind faults affecting the Last Glacial Transgressive Surface in the offshore Western Transverse Ranges (Southern California, US). The authors correlate these faults with different onshore thrust faults; provide evidence for different deformational events with large vertical uplifts (1-10 m); discuss the migration of the active deformation and shortening rates; infer the deep fault structure based on surface deformation; correlate events identified offshore with events described in onshore paleoseismological studies; and propose that, in case the different segments rupture in concert, they could produce a large earthquake (>Mw 7.5).

Singleton et al. investigate the characteristics of faulting and stratigraphic architecture beneath a pull-apart basin in San Diego Bay (Southern California, US) combining reprocessed legacy airgun multi-channel seismic profiles and highresolution Chirp data, with age and lithology controls from geotechnical boreholes and shallow sub-surface vibracores. The interpretation and analysis of this dataset has resulted in mapped stratigraphy within the subsiding basin, mapped active faults, and a kinematic fault analysis. Based on this information, the authors propose that the San Diego bay pullapart basin is divided into two sub-basins bounded by faults with different orientations and propose a connection between the Rose Canyon and San Miguel-Vallecitos main fault systems with implications for regional earthquake hazards.

\section{AUTHOR CONTRIBUTIONS}

HP, SM-L, JM, FM and PV edited the Research Topic "Submarine Active Faults: From Regional Observations to Seismic Hazard Characterization". All the authors listed have made a substantial direct and intellectual contribution to the work and approved it for publication.

\section{FUNDING}

The Research Topic Editorial activities of HP were supported by the European Union's Horizon 2020 research and innovation programme under grant agreement No H2020-MSCA-IF-2014 657769 and by the Madrid Community's “Atracción de Talento Investigador" call 2018 programme under the grant 2018-T1/ AMB-11039, and of SM-L were supported by the MICINN "Juan de la Cierva Incorporación” grant (IJCI-2017-33838) and by the ICM 'Severo Ochoa Centre of Excellence' accreditation, of the Spanish "Ministerio de Ciencia, Innovación y Universidades" 2020-2023 (CEX2019-000928-S).

\section{ACKNOWLEDGMENTS}

We thank all the authors for their valuable contributions to this Research Topic, the reviewers who shared their valuable time to improve the manuscripts, and the members of Frontiers Team and the Editor in Chief for their help at different stages of preparing this collection during the challenging years 2020 and 2021. We also want to specially thank Laura Gómez de la Peña for her collaboration in the initial discussion of the Research Topic.

Conflict of Interest: The authors declare that the research was conducted in the absence of any commercial or financial relationships that could be construed as a potential conflict of interest.

Publisher's Note: All claims expressed in this article are solely those of the authors and do not necessarily represent those of their affiliated organizations, or those of the publisher, the editors and the reviewers. Any product that may be evaluated in this article, or claim that may be made by its manufacturer, is not guaranteed or endorsed by the publisher.

Copyright (c) 2021 Perea, Martínez-Loriente, Maloney, Maesano and Vannucchi. This is an open-access article distributed under the terms of the Creative Commons Attribution License (CC BY). The use, distribution or reproduction in other forums is permitted, provided the original author(s) and the copyright owner(s) are credited and that the original publication in this journal is cited, in accordance with accepted academic practice. No use, distribution or reproduction is permitted which does not comply with these terms. 